\title{
MANEJO QUÍMICO DA FERRUGEM ASIÁTICA DA SOJA
}

\author{
Fernanda Carolina Cerutti ${ }^{1}$ \\ Alexandre Luis Muller ${ }^{2}$ \\ Dyogo Bortot Brustolin 3
}

RESUMO: O objetivo do presente trabalho foi avaliar a eficácia da utilização de diferentes princípios ativos no controle químico da ferrugem asiática em lavouras do oeste paranaense. $O$ experimento foi conduzido na estação experimental da MBF Pesquisas Agronômicas no município de Maripá, no período de novembro de 2020 a abril de 2021. $\mathrm{O}$ delineamento experimental utilizado foi blocos casualisados contendo 5 tratamentos com 4 repetições, os tratamentos foram compostos por uma testemunha absoluta e quatro tratamentos químicos com diferentes princípios ativos. As aplicações de fungicida iniciaram aos 45 dias após a emergência, seguido de mais duas aplicações com 14 dias de carência entre elas. Os parâmetros analisados foram a incidência e severidade da ferrugem asiática, produtividade e massa de mil grãos. Os resultados foram submetidos à análise de variância e comparados pelo teste de Tukey a 5\% utilizado o software AgroEstat. Nas avaliações aos 2I dias após a aplicação houve diferença entre os tratamentos e a testemunha. Não houve diferença de produtividade entre os tratamentos, mas na massa de mil grãos o tratamento 4 foi superior aos demais. As condições climáticas durante a condução do experimento influenciaram nos resultados da incidência de ferrugem asiática, da produtividade e da massa de mil grãos.

Palavras-chave: Fungicida. Phakopsora pachyrhizi. Glycine max.

ABSTRACT: Objective of the present work was to evaluate the effectiveness of the use of different active principles in the chemical control of Asian rust in crops in western Paraná. The experiment was carried out at the MBF Pesquisas Agronômicas experimental station in the municipality of Maripá, from November 2020 to April 2021. The experimental design used randomized blocks containing 5 treatments with 4 repetitions, the treatments were composed by an absolute witness and four chemical treatments with

\footnotetext{
${ }^{1}$ Acadêmica do curso de Agronomia da Escola de Ciências da Vida da Pontifícia Universidade Católica do Paraná - PUCPR, Câmpus Toledo, Paraná. E-mail: fercerutti28@gmail.com.

${ }^{2}$ Professor Dr. do curso de Agronomia da Escola de Ciências da Vida da Pontifícia Universidade Católica do Paraná - PUCPR, Câmpus Toledo, Paraná. E-mail: alexandre.luis@pucpr.br.

3 Mestre em Agronomia pela Universidade Estadual do Oeste do Paraná - Unioeste. E-mail: d_bortot@hotmail.com.
} 
different active ingredients. Fungicide applications started 45 days after emergence, followed by two more applications with a I4-day grace period between them. The parameters analyzed were the incidence and severity of Asian rust, productivity, and mass of a thousand grains. The results were subjected to analysis of variance and compared by Tukey's test at 5\% using the AgroEstat software. In the evaluations at 21 days after the application, there was a difference between the treatments and the witness. There was no difference in productivity between treatments, but in the mass of a thousand grains, treatment 4 was superior to the others. The climatic conditions during the conduct of the experiment influenced the results of the incidence of Asian rust, productivity, and mass of a thousand grains.

Keywords: Fungicide. Phakopsora pachyrhizi. Glycine max.

\section{INTRODUÇÃO}

O Brasil é considerado o maior produtor de soja (Glycine max) do mundo, esta cultura também é a principal cultivada no país e representa cerca de 50\% da colheita de grãos (CONAB, 202I). Segundo o $7^{\circ}$ levantamento da safra de grãos divulgado pela Conab (2021), estima-se uma produção de 135,5 milhões de toneladas, representando um aumento de 8,6\% em relação à safra anterior.

$\mathrm{Na}$ busca por manter as altas produtividades e a lucratividade da produção é essencial que o ciclo da cultura decorra com o mínimo de interferências negativas tornando o controle de doenças indispensável. Uma das doenças mais temida nas últimas décadas é a ferrugem asiática da soja causada pelo fungo Phakopsora pachyrhizi, que desde sua identificação há 20 anos, já foi responsável por perdas que excedem a 150 bilhões de reais (IGLESIAS, 2020). Além do impacto financeiro, a ferrugem asiática da soja pode provocar perdas de produtividade de até 90\% (GODOY et al., 2016).

As circunstâncias que propiciam a ocorrência e progressão desta doença são temperaturas entre 15 e $28{ }^{\circ} \mathrm{C}$ e ambientes com umidades relativas elevadas ( 75 a $80 \%$ ). Os sintomas podem acontecer em qualquer período do ciclo fenológico da cultura, com maior regularidade nas plantas próximas à floração e nas folhas inferiores da planta (GRIGOLLI, 2018). Godoy et al. (2019) relata que os primeiros sintomas da doença são pequenas lesões foliares, de coloração castanha a marrom-escura e nos casos mais severos 
pode ocorrer desfolha precoce, ocasionando o comprometimento da formação, enchimento de vagens e o peso final do grão.

No Brasil os métodos de manejo mais utilizados incluem o vazio sanitário, período de no mínimo 6o dias sem plantas de soja vivas no campo, visando controlar a quantidade do inóculo do fungo, a escolha de cultivares com genes resistentes, o emprego de cultivares de ciclo precoce, o monitoramento da lavoura desde o início do desenvolvimento da cultura, a aplicação do controle químico preventivamente ou no início dos sintomas e a diminuição do período de semeadura pretendendo diminuir o número de aplicações de fungicidas ao longo da safra tendo como objetivo atrasar a distinção de populações do fungo resistentes ou menos sensíveis ao controle químico (EMBRAPA SOJA, 2013).

Atentando que hoje o principal meio de controle da ferrugem asiática se dá pela utilização de fungicidas foliares, o uso constante de uma mesma classe ou mecanismo de ação neste manejo pode estimular a seleção de fungos resistentes, a fim de diminuir essa resistência, uma das estratégias é a rotação e mistura de diferentes mecanismos de ação (ABAG, $[2020])$.

McGrath (2004), em seus estudos faz a classificação dos fungicidas conforme sua atividade, caracterizando-os conforme seu mecanismo de ação. Podendo ser fungicidas multi sítios, com atividade em vários locais da planta, fazendo com que mais fungos em diferentes classes sejam afetados ou fungicidas de sítio-específicos, sendo estes aqueles ativos contra apenas um ponto em uma via metabólica, uma única enzima ou proteína crítica fundamental para o fungo, estes então têm maior possibilidade de ter sua ação superada visto que uma única mutação no patógeno normalmente possibilita a ele criar resistência.

Entre os mecanismos de ação pertencentes aos sítio-específicos utilizados no controle da ferrugem asiática Godoy et al. (2020) destaca os inibidores da desmetilação (IDM, "triazóis"), os inibidores de quinona externa (IQe, "estrobilurinas") e os inibidores da enzima succinato desidrogenase (ISDH, “carboxamidas”). 
Visando o aumento da produtividade e sanidade no cultivo da soja, o presente trabalho teve como objetivo avaliar a eficácia da utilização de diferentes princípios ativos no controle químico da ferrugem asiática em lavouras do oeste paranaense.

\section{MATERIAL E MÉTODOS}

O experimento foi conduzido na estação experimental da MBF Pesquisas Agronômicas no município de Maripá, no período de novembro de 2020 a abril de 2021. A altitude da propriedade é de 430 metros, e fica localizada sob as coordenadas 24 3I' 50" S e $53^{\circ} 4 \mathrm{I}^{\prime} 35^{\prime \prime} \mathrm{W}$. O solo do local está classificado como Latossolo Vermelho Distroférrico (EMBRAPA, 2012) e clima Cfa, subtropical úmido caracterizado por temperaturas médias acima de $22^{\circ} \mathrm{C}$ nos meses mais quentes (ITC, 2008).

Inicialmente, antes da implantação do experimento, a adubação da área foi realizada de acordo com o resultado obtido em análise de solo. A implantação ocorreu no dia 22 de novembro de 2020 , em semeadura tardia, visando aumentar a probabilidade de incidência da ferrugem, evitando o escape que ocorre nas primeiras semeaduras (GODOY et al., 2018).

A semeadura empregou o sistema de plantio direto utilizando a cultivar de soja MON 5947 IPRO de ciclo médio, no espaçamento de 0,45m entre linhas e densidade de I2 sementes por metro linear. A área experimental foi constituída por parcelas de 6 metros de comprimento por 3 metros de largura, totalizando $18 \mathrm{~m}^{2}$ cada.

O delineamento experimental utilizado foi blocos casualisados contendo 5 tratamentos com 4 repetições (Tabela $\mathrm{I}$ ). As aplicações de fungicida se iniciaram aos 45 dias após a emergência (DAE), os períodos entre a primeira e a segunda, e entre a segunda e terceira aplicação foram de 14 dias cada.

Tabela I. Formulação dos produtos testados no experimento com os seus devidos ingredientes ativos, doses e adjuvantes utilizados. Os tratamentos estão divididos em Tratamento I ( $\left.\mathrm{T}_{\mathrm{I}}\right)$, Tratamento $2\left(\mathrm{~T}_{2}\right)$, Tratamento $3\left(\mathrm{~T}_{3}\right)$, Tratamento $4\left(\mathrm{~T}_{4}\right)$ e Tratamento $5\left(\mathrm{~T}_{5}\right)$. 


\begin{tabular}{|c|c|c|c|c|c|}
\hline Tratamentos & Ingrediente Ativo & $\begin{array}{c}\text { Dose } \\
(\mathrm{L} \text { ou } \mathrm{Kg} / \mathrm{ha})\end{array}$ & Adjuvante* & $\begin{array}{c}\text { Dose } \\
\text { Adjuvante } \\
\text { Liha ou } \% \\
\text { vy) }\end{array}$ & $\begin{array}{l}\text { Estadio } \\
\text { Apliara }\end{array}$ \\
\hline T1 & Testemuna absoluta & - & - & - & $=$ \\
\hline \multirow[t]{3}{*}{$\mathrm{T}$} & $\begin{array}{c}\text { Bixafen + Proticonanol + } \\
\text { Tifoxtrubina / Cloreto de } \\
\text { bencalonio }\end{array}$ & 0,5 & $\begin{array}{l}\text { Ester inetilico } \\
\text { de óleo de soja }\end{array}$ & $0,25 \%$ & $45 \mathrm{DAE}$ \\
\hline & $\begin{array}{c}\text { Bixafen + Proticonawol + } \\
\text { Tifoxtrubina / Cloreto de } \\
\text { bencalconio }\end{array}$ & 0,5 & $\begin{array}{l}\text { Ester metilio } \\
\text { de óleo de soja }\end{array}$ & $0,25 \%$ & $59 \mathrm{DAE}$ \\
\hline & $\begin{array}{c}\text { Epoxiconawol + Fluxapiroxade + } \\
\text { piraclostrobina }\end{array}$ & 1. & Oleo mineral & 0,25 & $73 \mathrm{DAE}$ \\
\hline \multirow{4}{*}{ T3 } & Solatenol + Ciproconanol + & & & & \\
\hline & $\begin{array}{l}\text { Difenoconazol/Cloreto de } \\
\text { benzalconio }\end{array}$ & 0,5 & Oleo mineral & 0,25 & $45 \mathrm{DAE}$ \\
\hline & $\begin{array}{c}\text { Bixafen + Proticonawl }+ \\
\text { Tifoxtrubina / Cloreto de } \\
\text { benzalonio }\end{array}$ & 0,5 & Oleo mineral & 0,25 & $59 \mathrm{DAE}$ \\
\hline & $\begin{array}{c}\text { Epoxiconawol + Fluxapiroxade + } \\
\text { piralostrobina }\end{array}$ & 1. & Oleo mineral & 0,25 & $73 \mathrm{DAE}$ \\
\hline \multirow[t]{3}{*}{$\mathrm{I} 4$} & $\begin{array}{c}\text { Solatenol + Ciproconawol+ } \\
\text { Difenoconazol / Clorotalonil }\end{array}$ & $0,5+1$ & $\begin{array}{l}\text { Ester iletilio } \\
\text { deoleo desoja }\end{array}$ & $0,25 \%$ & $45 \mathrm{DAE}$ \\
\hline & $\begin{array}{c}\text { Solatenol + Protioconawol } \\
\text { Clowtalonil }\end{array}$ & $0,45+1$ & $\begin{array}{l}\text { Ester inetilico } \\
\text { de oleo de soja }\end{array}$ & $0,25 \%$ & $59 \mathrm{DAE}$ \\
\hline & $\begin{array}{c}\text { Epoxiconazol + Fluxapiroxade + } \\
\text { piralostrobina }\end{array}$ & 1. & Oleo mineral & 0,25 & $73 \mathrm{DAE}$ \\
\hline \multirow[t]{3}{*}{ T5 } & $\begin{array}{c}\text { Solatenol + Ciproconamol + } \\
\text { Difenoconazol / Clorotalonil }\end{array}$ & $0,5+1$ & $\begin{array}{l}\text { Ester iletilico } \\
\text { de dleo de soja }\end{array}$ & $0,25 \%$ & $45 \mathrm{DAE}$ \\
\hline & $\begin{array}{c}\text { Solatenol + Protioconazol } \\
\text { Clorotalonil }\end{array}$ & $0,45+1$ & $\begin{array}{l}\text { Ester matilico } \\
\text { de óleo de soja }\end{array}$ & $0,25 \%$ & $59 \mathrm{DAE}$ \\
\hline & $\begin{array}{c}\text { Difenoconawole + Ciproconawole } \\
\text { Clorotalonil }\end{array}$ & $0,3+1,0$ & 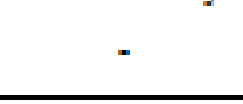 & - & $73 \mathrm{DAE}$ \\
\hline
\end{tabular}

* Adjuvantes escolhidos conforme recomendação da marca.

Fonte: o autor, 2021.

Para as pulverizações foi utilizado um pulverizador pressurizado com $\mathrm{CO}_{2}$, utilizando uma barra contendo 6 pontas $\mathrm{Jacto}^{\circledR}$, do tipo leque simples, modelo irooz. $\mathrm{O}$ espaçamento foi de $0,50 \mathrm{~m}$ entre bicos e o volume de calda foi ajustado para $150 \mathrm{~L} \mathrm{ha}^{-1}$.

As avaliações para determinação da necessidade de aplicação foram realizadas de forma visual aos 7, I4, 21, 28 e 35 dias após a última aplicação (DAA) com base na escala 
diagramática de severidade da ferrugem asiática na cultura da soja elaborada por Godoy et al. (2006) (Figura I).

Figura or. Escala diagramática de severidade da ferrugem asiática na cultura da soja.

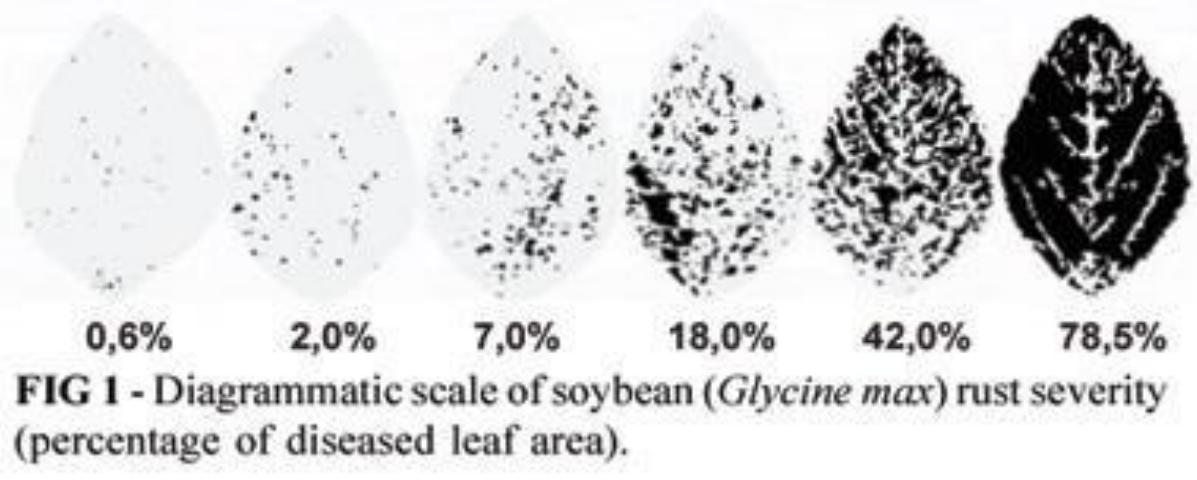

Fonte: Godoy et al., 2006.

Quando a cultura atingiu a maturidade fisiológica foram colhidas as 3 linhas centrais com 5 metros de comprimento, após a colheita as amostras foram trilhadas, pesadas e tiveram sua umidade corrigida. Posteriormente determinou-se a produtividade (kg. ha $\left.{ }^{-1}\right)$ e a massa de mil grãos (g).

Os resultados obtidos neste trabalho foram submetidos à análise de variância pelo teste $\mathrm{F}$ e quando significativas as médias foram comparadas pelo teste de Tukey a $5 \%$ de probabilidade. Para a realização da análise estatística, foi utilizado o software AgroEstat Sistema para Análises Estatísticas de Ensaios Agronômicos, na versão i.I.o.712 (BARBOSA, 2015).

\section{RESULTADOS E DISCUSSÃO}

Nas avaliações de severidade da ferrugem asiática realizadas e apresentadas na Figura 2, podemos perceber que não há uma diferença significativa na maioria das avaliações entre os tratamentos, e entre os tratamentos com controle químico e a testemunha absoluta. 
Figura 2. Resultados das notas de severidade de ferrugem com base na escala diagramática das avaliações realizadas aos 7, I4, 2I, 28 e 35 dias após a aplicação dos tratamentos.

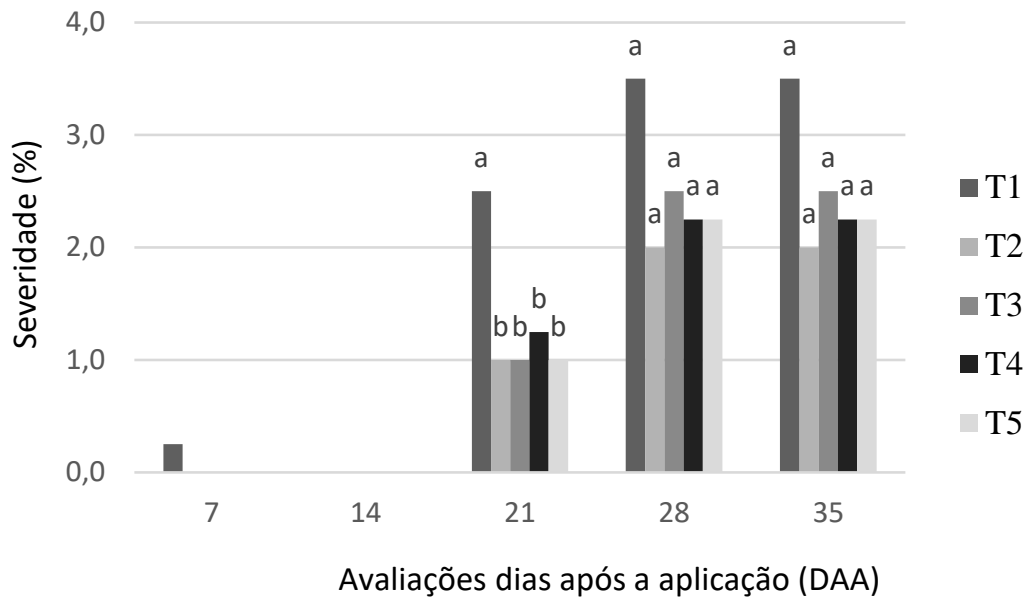

Fonte: o autor, 2021.

Inicialmente as avaliações não mostraram severidade da doença, mas no decorrer destas podemos verificar (Figura 2) que somente aos 2i dias após a aplicação (DAA) a testemunha apresentou maior severidade em relação aos outros tratamentos que utilizaram o controle químico. Nas avaliações seguintes também não houve variação entre tratamentos. Este resultado pode estar associado ao pouco residual do produto nas últimas avaliações e as

condições climáticas de temperatura e umidade relativa estarem desfavoráveis ao surgimento e proliferação da ferrugem.

Segundo Godoy et al. (2020) o intervalo de aplicação foi estabelecido em I4 dias devido a menor sensibilidade do fungo P. pachyrhizi aos fungicidas hoje disponíveis. Assim como ocorreu no presente trabalho, aos 2I dias após a aplicação o residual de produto presente na planta não é suficiente para conter o patógeno que apresenta menor sensibilidade aos mecanismos de ação utilizados.

Melching et al. (1989) estudando a epidemiologia da ferrugem asiática da soja observou que poucas lesões primárias se desenvolveram em temperaturas de 18 a $26,5^{\circ} \mathrm{C}$. Enquanto Alves et al. (2007) observou menor intensidade em temperaturas próximas a $30 \mathrm{e}$ I5 ․ C. Ambos os autores concordam que em períodos de molhamento foliar abaixo de 6 horas houve menor intensidade da doença. Estes resultados corroboram com os obtidos no 
presente trabalho pois durante a condução do experimento também houve um período de altas temperaturas e baixa umidade que reduziram a intensidade da doença.

Outro autor que obteve resultados similares os do presente trabalho foi Peransoni et al. (2020) afirma que a infecção, reprodução e disseminação da ferrugem asiática está relacionada à presença de moderadas chuvas com molhamento foliar contínuo em torno de

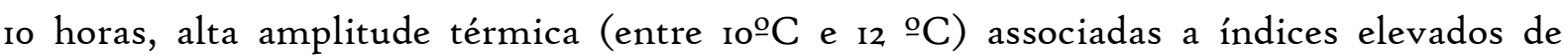
umidade incrementados pela elevação de esporos na atmosfera.

Os resultados obtidos neste trabalho estão de acordo com ensaios realizados por Godoy et al. (2019) que apesar do plantio tardio evitando o escape da doença também teve tratamentos com baixa severidade que impediram uma avaliação de seu potencial preventivo.

Após a análise estatística das avaliações, os resultados obtidos em produtividade e massa de mil grãos podem ser observados na Tabela 2. Verificou-se que não houve diferença significativa entre os tratamentos na análise da produtividade (PROD), diferente dos resultados da massa de mil grãos (MMG) onde houve diferença.

Tabela 2. Resultados obtidos na análise estatística de produtividade (PROD, kg. ha ${ }^{-1}$ ) e massa de mil grãos (MMG, g).

\begin{tabular}{|c|c|c|c|}
\hline \multirow{2}{*}{$\begin{array}{c}\text { Formas } d= \\
\text { wariag } \equiv 0\end{array}$} & \multirow{2}{*}{$G$} & \multicolumn{2}{|c|}{ Quadrado MLËdio } \\
\hline & & PFOD & MnLG \\
\hline Trat:anr=nto & \pm & $0_{3} 37^{m a}$ & $1 \div 3.564$ \\
\hline $\mathbf{R} \equiv \mathrm{p} \equiv \mathrm{ti} \rho \mathbf{D} \equiv=$ & 3. & $1.96^{m}$ & $0.1 \mathrm{~g}^{\mathrm{me}}$ \\
\hline Residuo & 12 & 1191447 & 1.01 \\
\hline \multirow{4}{*}{ Trat:annento } & 1 & $\begin{array}{l}281+75 a \\
30 \div 2,50 a\end{array}$ & $\begin{array}{l}161,50 \mathrm{c} \\
170,00 \mathrm{~b}\end{array}$ \\
\hline & 3 & $2931.50 \mathrm{a}$ & $160.00=$ \\
\hline & \pm & $3079.75 a$ & $173.75 \equiv$ \\
\hline & 5 & $3013.00 \mathrm{a}$ & $170.50 \mathrm{~b}$ \\
\hline MLEdia Gimal & & 2976,3 & 167.15 \\
\hline ow mes & & 1159 & 0.5 \\
\hline
\end{tabular}

Fonte: o autor, 2021.

PROD: Produtividade. MMG: Massa de mil grãos. Médias seguidas pela mesma letra, na coluna, não diferem entre si pelo teste de Tukey a $5 \%$ de probabilidade. Ns, *, **, 
não significativo, significativo a 5\% e a I\% respectivamente. GL: Grau de liberdade. CV: Coeficiente de variação.

Na variável massa de mil grãos (Tabela 2), podemos observar que se sobressai o tratamento 4 como o melhor em relação aos demais, seguido dos tratamentos 2 e 5 , que não obtiveram diferença entre si, e por fim, os tratamentos i e 3 que comparado aos demais podem ser considerados como os piores resultados nesta análise.

Segundo resultados obtidos por Balzan et al. (2018) a massa de mil grãos dos tratamentos químicos obteve diferença significativa quando comparada a testemunha, comprovando a eficiência da aplicação de fungicidas para controle da ferrugem asiática da soja. O que diverge do resultado obtido no presente trabalho onde a testemunha e o tratamento 3 não tiveram diferenças significativas entre si.

Os resultados de produtividade alcançados no seguinte trabalho não apresentaram diferença significativa entre tratamentos. Segundo dados do Departamento de Economia Rural (2021), quando comparada a safra de 2019/2020 houve uma redução de até $4 \%$ da produtividade do estado, esta redução está associada tanto ao clima quanto à ocorrência de pragas. No decorrer do desenvolvimento da cultura várias situações adversas principalmente regime de chuva irregular e altas temperaturas contribuíram para o resultado obtido no experimento.

Segundo boletins agro meteorológicos do IDR-Paraná (202I) no mês de janeiro ocorreu além de um excesso de chuva, que em muitas cidades ultrapassou a média histórica, um período chuvoso ininterrupto e baixo índice de radiação solar, com até mais de 20 dias consecutivos de chuva em algumas cidades. Em fevereiro houve uma redução das chuvas ficando abaixo da média esperada para o mês, os muitos dias ensolarados provocaram o aumento das temperaturas máximas na maioria das cidades do estado, em comparação às médias históricas. Essa condição se agravou ainda mais no mês de março, onde não houve chuvas consideráveis e manteve-se as altas temperaturas.

A adversidade do ambiente durante o ciclo da cultura avaliada neste experimento afetou seu desenvolvimento e sua produtividade. Quando exposta a altas temperaturas o florescimento da soja pode ocorrer antes do tempo acarretando a diminuição na altura da 
planta, se além de altas temperaturas ocorrem ao mesmo tempo carência hídrica e/ou fotoperiódica durante as fases de crescimento este problema pode ser elevado (FARIAS et al., 2007).

Nos períodos de desenvolvimento da soja, a disponibilidade de água é essencial para a germinação/emergência, floração e enchimento de grãos. Com o desenvolvimento da planta a necessidade de água aumenta atingindo o máximo durante a floração e enchimento de grãos. Neste período, déficits hídricos expressivos, como os que ocorreram nos meses de fevereiro e março deste ano, ocasionam alterações fisiológicas na planta como a queda prematura de folhas, flores e abortamento de vagens resultando na redução do rendimento de grãos (EMBRAPA SOJA, 2013).

Dal Pogetto et al. (2012) afirmam que a pulverização de fungicida contra o fungo $P$. pachyrhizi é indispensável para diminuir as perdas na produtividade provocadas pela ferrugem asiática da soja. A desfolha precoce é o principal dano ocasionado pela ferrugem, pois impede a completa formação dos grãos e consequentemente a reduz a produtividade (GODOY et al., 2016) citado por GODOY et al. (2020). Apesar de não ter sido observado altos índices de incidência da doença, neste trabalho foi notada uma relação positiva quanto a aplicação de controle químico.

\section{CONCLUSÃO}

A utilização de diferentes princípios ativos no manejo químico da ferrugem asiática mostrou relação positiva quando comparado à testemunha nas avaliações de severidade aos 2I dias após a aplicação, mas não foi possível avaliar diferença entre tratamentos.

Os resultados de produtividade não apresentaram diferença significativa. Houve um acréscimo na massa de mil grãos no tratamento 4 em relação aos demais.

O controle químico representa uma das formas de manejo da ferrugem asiática, para uma maior eficiência deve ser associada mais de uma estratégia de controle. 


\section{REFERÊNCIAS BIBLIOGRÁFICAS}

ABAG. O Futuro da Soja Nacional: impactos socioeconômicos da ferrugem asiática na cadeia da soja nos próximos dez anos. Impactos socioeconômicos da Ferrugem Asiática na cadeia da soja nos próximos dez anos. [2020]. São Paulo, 28 p.

AlveS, M. C.; POZZA, E. A.; FERREIRA, J. B.; ARAÚJO, D. V.; et al. Intensidade da ferrugem asiática (Phakopsora pachyrhizi H. Sydow \& P. Sydow) da soja [Glycine max (L.) Merr.] nas cultivares Conquista, savana e suprema sob diferentes temperaturas e períodos de molhamento foliar. Summa Phytopathologica, v.33, n.3, p.239-244, 2007.

BALZAN, Fabricio et al. Avaliação da Produtividade de Soja com Aplicações de Diferentes Combinações de Fungicidas. $5^{\circ}$ AGROTEC. 2018, Chapecó. Disponível em: https://eventos.uceff.edu.br/eventosfai_dados/artigos/agrotec2018/871.pdf. Acesso em: 30 abr. 2021.

BARBOSA, J. C.; Maldonado Junior, W.; AgroEstat: sistema para análises estatísticas de ensaios agronômicos. 2015. Jaboticabal, FCAV/UNESP. 396p.

CONAB. Companhia Nacional de Abastecimento. Acompanhamento da Safra Brasileira de Grãos. Brasília, DF, v. 8, p. 86-IoI. Safra 2020/2I, n. 7, sétimo levantamento, abr. 202I.

CONAB. Companhia Nacional de Abastecimento. Produção de grãos pela primeira vez na história deve superar 270 milhões de t. 2021. Disponível em: https://www.conab.gov.br/ultimas-noticias/3915-producao-de-graos-pela-primeira-vezna-historia-deve-superar-270-milhoes-de-toneladas. Acesso em: I9 abr. 2021.

DEPARTAMENTO DE ECONOMIA RURAL (DERAL). Agricultura e Abastecimento. Paraná deve colher 23,9 milhões de toneladas de grãos. 2021. Disponível em: http://www.agricultura.pr.gov.br/Noticia/Parana-deve-colher-239-milhoes-detoneladas-de-graos. Acesso em: 30 abr. 2021. 
EMBRAPA Empresa Brasileira de Pesquisa Agropecuária (org.) / Humberto Gonçalves dos Santos. Sistema brasileiro de classificação de solos. SIBCS. 5.ed., rev. e ampl. Brasília, DF: Embrapa solos, 2018.

EMBRAPA SOJA (org.). Tecnologias de Produção de Soja - Região Central do Brasil 2014. Londrina: Embrapa Soja, 2013. 265 p. Sistema de Produção, ı6. Disponível em: https://ainfo.cnptia.embrapa.br/digital/bitstream/item/95489/I/SP-r6-online.pdf. Acesso em: 20 abr. 2021.

FARIAS, José Renato Bouças et al. Ecofisiologia da soja. Londrina: Embrapa Soja, 2007. 8 p. (Circular técnica, 48).

GOdOY, C. V.; AlmeidA, A. M. R.; COSTAMilan, L. M.; MEYER, M. C.; et al. Doenças da soja. In: AMORIM, L.; REZENDE, J. A. M.; BERGAMIN FILHO, A.; CAMARGO, L. E. A. (Ed.). Manual de fitopatologia: doenças das plantas cultivadas. 5. ed. v. 2. p. 657-675.Ouro Fino: Agronômica Ceres, 2016.

GODOY, Cláudia V. et al. Escala diagramática para avaliação da severidade da ferrugem da soja. Fitopatologia Brasileira, Brasília, v. 31, 63-68 p. Fev. 2006. https://doi.org/10.1590/Soroo-4158200600oiooori

GODOY, Claudia Vieira et al. Ensaio Cooperativo para Avaliação da Eficiência de Fungicidas no Controle da Ferrugem-Asiática da Soja, Phakopsora Pachyrhizi, na Safra 2015/16, em Londrina, PR. In: XXXV Reunião de Pesquisa de Soja, 2016, LondrinaPr. Resumos expandidos [da] XXXV Reunião de Pesquisa de Soja. Embrapa Soja, 2or6. p. 94-96.

GODOY, Cláudia Vieira et al. Eficiência de fungicidas multissítios no controle da ferrugem-asiática da soja, Phakopsora pachyrhizi, na safra 2017/18: resultados sumarizados dos ensaios cooperativos. Londrina-Pr: Embrapa Soja, 2018. I7 p. (Circular técnica, 144).

GODOY, Cláudia Vieira et al. Eficiência de fungicidas para o controle da ferrugemasiática da soja, Phakopsora pachyrhizi, na safra 2018/19: Resultados sumarizados dos ensaios cooperativos. Londrina-Pr: Embrapa Soja, 2019. Io p. (Circular técnica, I48). 
GODOY, Cláudia Vieira et al. Ferrugem-asiática da soja: bases para o manejo da doença e estratégias antirresistência. Londrina: Embrapa Soja, 2020. 39 p. (Embrapa Soja. Documentos, 428).

GRIGOLLI, José Fernando Jurca et al (ed.). Tecnologia e Produção: Soja 2017/2018. Curitiba: Midiograf, 2018. p. 209.

IDR-PARANÁ. Instituto de Desenvolvimento Rural do Paraná. Agrometeorologia. 202I. Disponível em: http://www.idrparana.pr.gov.br/Editoria/Agrometeorologia\#. Acesso em: 25 abr. 2021.

IGLESIAS, Rafael. Ferrugem da soja já causou R $\mathbf{1 5 0}$ bilhões em prejuízos no Brasil. 2020. Revista Cultivar. Disponível em: https://www.grupocultivar.com.br/noticias/ferrugemda-soja-ja-causou-r-I5o-bilhoes-em-prejuizos-nobrasil\#: :text=Ferrugem\%2oda\%20soja\%20j\%C3\%Ar\%2ocausou\%2oR\%24\%20150\%20bilh\% $\mathrm{C}_{3 \% B}$ 5es\%2oem\%2opreju\%C3\%ADzos\%2ono\%2oBrasil,01\%2F10\%2F2020\&text $=$ Phakopsora\%2opachyrhizi.\&text $=$ Desde\%2oque\%2ofoi\%2oidentifi cada\%2ono,bilh\%C3\%B5es\%20no\%2ocultivo\%2oda\%20soja. Acesso em: 23 abr. 2021.

ITC; Instituto de Terras, Cartografia e Geociências. Clima - Estado do Paraná. 2008. Dispnível em: http://www.iat.pr.gov.br/sites/aguaterra/arquivos_restritos/files/documento/2020-07/mapa_climas_a3.pdf. Acesso em: 23 abr. 2021.

MCGRATH, Margaret Tuttle. What are Fungicides. The Plant Health Instructor, [S.L.], 2004. Scientific Societies. http://dx.doi.org/ro.1094/phi-i-2004-0825-or.

MELCHING, J.S.; DOWLER, W.M.; KOOGLE, D.L.; ROYER, M.H. Effects of duration, frequency, and temperature of leaf wetness periods on soybean rust. Plant Disease, Saint Paul 73:117-122. 1989.

PERANSONI, Ademir de Cássio Machado et al. Condições Meteorológicas Associadas a Ocorrência da Ferrugem Asiática da Soja na Fase Assintomática. Geoambiente On-Line, Jataí-Go, n. 37, p. 238-26o. Ago, 2020. 